BMJ Surgery, Interventions, $\&$ Health Technologies

\title{
Age-stratified outcomes of bioprosthetic and mechanical aortic valve replacements in an Australian cohort of 13377 patients
}

\author{
Oluwadamisola Temilade Sotade (D) , ${ }^{1}$ Michael Falster (D) , ${ }^{1}$ Leonard N Girardi, ${ }^{2}$ \\ Sallie-Anne Pearson (D) , ${ }^{1}$ Louisa R Jorm (D) ${ }^{1}$
}

To cite: Sotade OT, Falster M, Girardi LN, et al. Age-stratified outcomes of bioprosthetic and mechanical aortic valve replacements in an Australian cohort of 13377 patients. BMJ Surg Interv Health Technologies 2020;2:e000036. doi:10.1136/ bmjsit-2020-000036

- Additional material is published online only. To view please visit the journal online (http://dx.doi.org/10.1136/ bmjsit-2020-000036)

Received 20 February 2020 Revised 26 June 2020 Accepted 06 August 2020

\section{Check for updates}

(C) Author(s) (or their employer(s)) 2020. Re-use permitted under CC BY-NC. No commercial re-use. See rights and permissions. Published by BMJ.

${ }^{1}$ Centre For Big Data Research in Health, University of New South Wales Faculty of Medicine, Sydney, New South Wales, Australia

${ }^{2}$ Cardiothoracic Surgery, Weill Cornell Medical College, New York, New York, USA

Correspondence to Oluwadamisola Temilade Sotade; o.sotade@unsw.edu.au

\section{ABSTRACT}

Objectives To quantify age-stratified outcomes of bioprosthetic valve (BV) and mechanical valve (MV) surgical aortic valve replacement (AVR) in Australian patients.

Design Retrospective cohort study using populationbased linked hospital morbidity and mortality data.

Setting Public and private hospitals.

Participants Patients aged 18 years and over undergoing AVR from 2001 to 2013, stratified by age (18-64 years; $65+$ years).

Main outcome measures Age-standardized index AVR rates; rates and multivariable-adjusted (age, sex, Charlson Comorbidity Index) incidence rate ratios (IRRs) for reoperation, incident cardiovascular events (hospitalization or death for acute myocardial infarction (AMI), stroke, major hemorrhage or thromboembolism) and mortality (cardiovascular and all-cause).

Results Our cohort comprised 13377 patients, of whom 3464 (26\%) were aged 18-64 years. Annual age-standardized AVR rates increased by $2.7 \%$ with BV implants increasing in both age groups. After 5 years of follow-up, patients implanted with BV had lower rates of stroke (IRR: $0.40,95 \% \mathrm{Cl} 0.27$ to 0.60 ) and hemorrhage (IRR: $0.36,95 \% \mathrm{Cl} 0.26$ to 0.50 ). Among patients $65+$ years, those implanted with BV had lower rates of AMI, hemorrhage, and cardiovascular and all-cause mortality than those implanted with MV (IRR: $0.71,95 \% \mathrm{Cl} 0.53$ to 0.96 ; IRR: $0.77,95 \% \mathrm{Cl} 0.62$ to 0.95 ; IRR: 0.80 , $95 \% \mathrm{Cl} 0.69$ to 0.92 and IRR: $0.85,95 \% \mathrm{Cl} 0.74$ to 0.97 , respectively). After 6-10 years of follow-up, reoperation rates among patients 18-64 years were markedly higher in those implanted with BV compared with MV (IRR: $5.48,95 \% \mathrm{Cl} 2.38$ to 12.62 ) and rates of AMI were lower among patients implanted with BV compared with MV (IRR: $0.49,95 \% \mathrm{Cl} 0.26$ to 0.94$)$. Among patients $65+$ years rates of cardiovascular and all-cause mortality remained significantly lower for patients implanted with BV compared with MV.

Conclusions This study provides real-world evidence of AVR use and outcomes. Use of BV implants is increasing irrespective of age. Valve choice in younger patients requires thorough evaluation of patient factors influencing both short-term outcomes and longer-term risks of reoperation, stroke and hemorrhage.

\section{Key messages}

What is already known about this subject?

- Use of bioprosthetic valve implants in patients aged less than 65 years is controversial, but there is a worldwide trend towards increased implantation of bioprosthetic valves particularly with the advent of transcatheter aortic valves.

\section{What are the new findings?}

- Patients aged 18-64 years receiving bioprosthetic compared with mechanical valves had an increased risk of reoperation after 5 years, but lower risk of stroke and hemorrhage within 5 years. Older patients $(65+)$ receiving bioprosthetic valves had lower rates of acute myocardial infarction, hemorrhage and mortality within 5 years, and lower rates of mortality after 5 years.

\section{How might these results affect future} research or surgical practice?

- Choice of valve implant in patients requires thorough evaluation of patient factors influencing both short-term outcomes and the longer-term risks of reoperation, stroke, hemorrhage and mortality. The introduction of transcatheter aortic valve replacement requires more research as outcomes might be different from surgically implanted bioprosthetic valves.

\section{INTRODUCTION}

Valvular heart diseases are increasing worldwide, with aortic stenosis (AS) being the most prevalent. ${ }^{1-3}$ Surgical aortic valve replacement (AVR) is the standard treatment for severe $\mathrm{AS}^{12}$ and is performed with bioprosthetic (BV) or mechanical (MV) valves. ${ }^{4}$ Historically, international guidelines recommended BV for patients aged 65 years and over due to their shorter life expectancy and reduced likelihood of valve degeneration requiring reoperation; ${ }^{5} \mathrm{MV}$ was recommended for patients under 65 years due to increased longevity of the valve, although it 
requires lifelong anticoagulant use and therefore poses the risk of major hemorrhage. ${ }^{4-6}$ Current guidelines have moved away from age-specific recommendations, and now stipulate the use of BV for patients with lower life expectancy and those unlikely to adhere to, or with major contraindications to, anticoagulant therapy. ${ }^{4} 7$ Early versions of bioprosthetic valves failed in as little as 5 years, particularly among young patients, ${ }^{89}$ and lasted for up to 10 years, while current valves last for up to 15 years. ${ }^{10} 11$ In the last decade, there has been increased use of BV worldwide ${ }^{12}$ coinciding with a substantial reduction in MV implantation. ${ }^{13-18}$

Outcomes of AVR are typically measured by short-term (30-90 days) or longer-term ( $\geq 12$ months) morbidity, mortality and reoperation rates. Most studies report on single-center, ${ }^{11}{ }^{19}$ restricted $^{1020-23}$ or small cohorts ${ }^{23}$ and most have less than 10 years of follow-up postimplantation. ${ }^{20} 2123$ Previous studies examining age-specific outcomes have shown patients receiving $\mathrm{BV}$ have fewer long-term anticoagulant-related events such as hemorrhage (a major driver of mortality), but significantly higher major adverse prosthesis-related events and reoperation. ${ }^{10} 142223$ Among studies examining outcomes across all age groups, the same findings were observed. ${ }^{11} 1924$ Recent systematic reviews examining outcomes in patients aged 50-70 years have conflicting conclusions around patient survival. ${ }^{25}{ }^{26} \mathrm{~A}$ review of observational studies found no significant differences in long-term patient survival based on valve type ${ }^{25}$ but a more recent analysis of randomized controlled trials (RCTs) and propensity score matched observational studies showed increased survival in patients receiving $\mathrm{MV}^{26}$

Valve choice in younger patients is of particular interest because of the potential trade-offs between reoperation risk with $\mathrm{BV}$ and the risk of major complications with $M V{ }^{27}$ Given the increasing prevalence of valvular heart disease ${ }^{28}$ it is important to assess the real-world impact of valve choice in relation to age. ${ }^{29}$ Furthermore, as transcatheter AVR (TAVR) is being adopted increasingly as a minimally invasive approach for bioprosthetic valves, it is important to establish a benchmark for outcomes of surgical AVR. ${ }^{13}{ }^{30}$ Therefore, we sought to use linked, administrative health data from the state of New South Wales (NSW), Australia, to provide real-world evidence on age-stratified outcomes of patients receiving BV and MV from surgical AVR.

\section{METHODS}

\section{Setting}

NSW is the largest state in Australia, with a population of 7.8 million people in 2016. Australia's healthcare system comprises both a universal publicly financed health sector and a private health sector. All residents are provided with free care in public hospitals but they can also take out private medical insurance giving them subsidized care for specific services, choice of provider and generally shorter wait times for elective services. ${ }^{31}$

\section{Study design and data sources}

We conducted a retrospective observational cohort study using whole-of-population linked administrative hospital and mortality data. We used the New South Wales (NSW) Admitted Patient Data Collection (APDC); regardless of patient insurance or hospital type, all services performed in NSW hospitals are captured in this collection. APDC data comprise records for all separations (discharges, transfers and deaths) from public and private hospitals, and day procedure centers in NSW. The APDC records up to 50 procedure codes, using the Australian Classification of Health Interventions (ACHI) ${ }^{32}$ and up to 51 diagnosis codes, using the International Classification of Diseases (ICD), 10th Revision, Australian Modification. ${ }^{32}$ These data were linked with the fact of death from the Registry of Births Deaths and Marriages (RBDM) mortality data file and cause of death from the Australian Bureau of Statistics (ABS) mortality data file. Data linkage was performed by the Centre for Health Record Linkage (CHeReL) ${ }^{33}$ The CHeReL uses probabilistic linkage procedures, and has a false-positive and false-negative rate of $0.5 \%{ }^{34}$

\section{Study cohort}

We identified all patients who underwent isolated and concomitant surgical AVR with bioprosthetic (ACHI code $38488-01$ ) or mechanical (38488-00) valves in any NSW hospital from July 2001 to June 2013. We defined each patient's 'index' AVR procedure as the first recorded within the study period. Where AVR procedure dates were missing $(n=1621)$, we used the principal procedure or episode start date. We excluded patients if they were aged under 18 years at the time of index procedure; if there was a secondary procedure code indicating the index procedure was a reoperation (38640-00); if there was a second AVR procedure recorded within the same hospital stay; or if the index AVR date occurred after a patient's recorded date of death (figure 1). Changes to the type of care within a hospital (eg, from acute to subacute care) and transfers between facilities were considered a continuation of the same hospital stay.

\section{Patient and hospital characteristics}

We characterized patients at their index admission according to demographic, hospital and episode characteristics. Patient Aboriginal and Torres Strait Islander status was initially examined, however was not included for further analysis due to low numbers. Patient comorbidities were identified using the Charlson Comorbidity Index (CCI $)^{35}$ based on all diagnoses in the index hospitalization and any other hospital stays in a 1-year lookback period. Patients' socioeconomic status was classified using the ABS Socio-Economic Index for Areas Index of Relative Social Disadvantage, based on their Statistical Local Area (SLA) of residence, and grouped into quintiles. ${ }^{36}$ Remoteness of residence was derived from the Accessibility/Remoteness Index of Australia, based on SLA of residence, and grouped into four categories (major city, inner regional, outer regional and remote/very 




Figure 1 Age-standardized rates of bioprosthetic and mechanical aortic valve implantations between financial years ending in 2002 and 2013, among all patients and stratified by age group.

remote) ${ }^{37}$ Hospital volume was calculated as the median annual number of AVR procedures performed across the study period and classified as high ( $\geq 100$ per year) and low ( $<100$ per year $)$.

\section{Outcome measures}

We identified reoperation as any subsequent AVR procedure over the study period, irrespective of valve type. We identified incident cardiovascular events based on literature $^{212238-42}$ as any emergency admission, or death, with a principal diagnosis/cause of death of acute myocardial infarction (AMI), stroke (infarction or hemorrhage), hemorrhage or thromboembolism (online supplemental table 1). We also classified mortality as cardiovascular (ICD codes I00-99) and all-cause mortality. ${ }^{43}$ Where patients had inconsistent death dates in the RBDM and ABS data sets, we used the RBDM date of death.

\section{Statistical analyses}

\section{Clinical and hospital characteristics}

We stratified patients by valve type and age group (18-64 years and 65 years and over). We chose the age cut-off of 65 years based on recommendations by the American Heart Association, American College of Cardiology and European Society of Cardiology. ${ }^{49}{ }^{44}$ We presented continuous data as median and IQR and expressed categorical data as proportions. All analyses were performed in R V.3.5.2.

\section{Procedure rates}

We calculated annual rates of index AVR implantation per 100000 population aged 18 years and over by Australian financial year from July 2001/2002 to June 2012/2013. We calculated overall rates and age-stratified rates (18-64 years; 65+ years) using NSW population estimates from the $\mathrm{ABS}^{45}$ and directly age standardized to single years of age in the 2001 Australian population. ${ }^{46}$

\section{Reoperation, incident cardiovascular events and mortality}

We calculated incident event rates for each outcome as the total number of first events (hospital admission or death for a specific cause) observed divided by total personyears of follow-up for each group. We calculated total person-years for each patient from their index AVR date, and ending at death or end of follow-up (30 June 2013), depending on which occurred first. For each outcome, we right censored patient follow-up time at the first event, death or end of follow-up. To compare incidence rates between patients receiving BV and MV, we calculated incidence rate ratios (IRRs) using Poisson models, on the count of incident events (in 5-year age brackets) with the sum of the follow-up time as an offset. Due to inconsistencies in rates over time, we partitioned the models into two time periods ( $\leq 5$ years and $6-10$ years) of follow-up. We adjusted for age, sex and CCI and unless otherwise stated, IRR results presented are fully adjusted. We used cumulative incidence function curves to examine the risk of reoperation and cardiovascular mortality, accounting for the competing risk of all-cause mortality and noncardiovascular mortality, respectively. We used KaplanMeier curves to examine all-cause mortality.

\section{Sensitivity analysis}

We conducted a sensitivity analysis to assess the impact of early mortality on the time-partitioned incident event rates, by excluding patients who died within 30 days of the index AVR procedure.

\section{RESULTS}

\section{Patient and hospital characteristics}

Our eligible study cohort comprised 13377 patients with index AVR procedures between 1 July 2001 and 30 June 2013, of whom $9500(71.0 \%)$ received BV implants and $3877(29.0 \%)$ received MV implants (online supplemental figure 1). The median age of patients undergoing AVR with BV implants was 76 years (IQR 69-81) compared with 65 years (IQR 55-74) for MV (table 1). A small proportion $(15.5 \%)$ of patients implanted with BV were aged $18-64$ years; $51.5 \%$ of patients $18-64$ years were implanted with MV. The proportion of patients with a CCI Score of 1 or more was similar across valve types 
Table 1 Patient and hospital characteristics at index aortic valve replacement (AVR) procedure

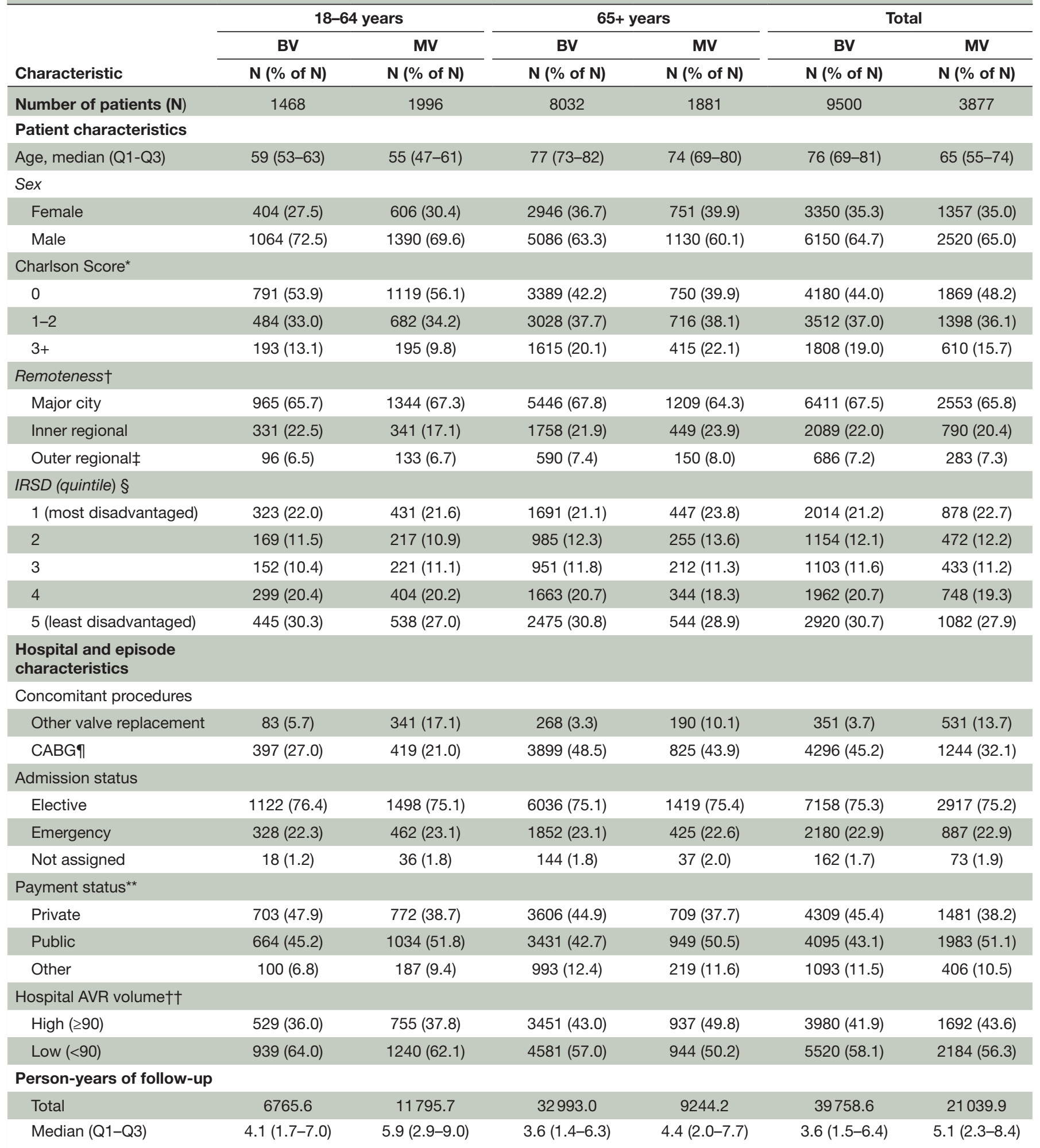

Note: missing data where $\%$ values do not add to $100 \%$

${ }^{*}$ Charlson Comorbidity Index calculated with a 1-year lookback, including index AVR admission and any admissions in the year prior †Accessibility/Remoteness Index of Australia

łncludes outer regional, remote and very remote

§IRSD: ABS Socio-Economic Index for Areas Index of Relative Social Disadvantage (SEIFA IRSD)

ICABG: coronary artery bypass graft

${ }^{* *}$ Other payment status on separation includes compensation (workers, NSW motor vehicle accident and other), Department of Veterans Affairs and Medicare ineligible

††Median annual number of AVR procedures performed classified as high ( $\geq 90$ per year) and low ( $<90$ per year)

ABS, Australian Bureau of Statistics; BV, bioprosthetic valve; MV, mechanical valve. 
( $56.0 \%$ for BV, $51.8 \%$ for MV). Overall, $41.4 \%$ of AVR patients had coronary artery bypass graft (CABG) procedures in the same hospital episode, with this being more prevalent in patients aged 65 years and over $(47.7 \%)$ than in younger patients $(23.6 \%)$. A greater proportion of patients receiving BV $(45.4 \%)$ than MV (38.2\%) were treated as private rather than public patients. The clinical profiles of patients undergoing AVR were consistent over the study period (online supplemental table 2). Patients had a median of 4.0 years IQR (1.7-7.0) follow-up from their index AVR procedure (median 3.6; IQR 1.5-6.4; maximum 12 for BV; median 5.1; IQR 2.3-8.4; maximum 12 for MV), for a total of 60798.5 years of follow-up.

\section{AVR procedure rates}

Age standardized AVR rates increased from 17 per 100000 persons in $2001 / 2002$ to 22 per 100000 persons in 2012/2013, an average $2.7 \%$ annual increase (figure 1). Rates of BV implantation doubled over the same period, from 9 to 18 per 100000 persons (an average increase of $6.1 \%$ per year) and MV implantation rates decreased from 7 to 4 per 100000 persons over the same period ( $4.7 \%$ annual decrease). Among patients aged 18-64 years, rates of MV implantation (4 per 100000 persons) were more than twice those for BV implantation (2 per 100000 persons) in 2001/2002 but these rates were similar by 2009/2010 ( 2 and 3 per 100000 persons for BV and MV, respectively) (online supplemental table 3 ).

\section{Reoperation rates}

In the first 5 years of follow-up, reoperation rates were lower for patients receiving BV compared with MV, across all ages (IRR: $0.65,95 \%$ CI 0.51 to 0.83 ) and among patients aged $18-64$ years (IRR: $0.77,95 \%$ CI 0.52 to 1.14 ) and 65 years and over (IRR: $0.61,95 \%$ CI 0.37 to 1.01 ) (table 2). However, the age-stratified findings were not statistically significant.

After 6-10 years of follow-up, the rate of reoperation among patients aged 18-64 years was significantly higher for patients implanted with BV compared with MV (IRR: $5.48,95 \%$ CI 2.38 to 12.62 ), but this finding was not observed among patients aged 65 years and over (IRR: $0.86,95 \%$ CI 0.45 to 1.65$)$.

The cumulative incidence functions for reoperation showed a low, and similar, probability of reoperation for both valve types and age groups in the first 5 years after surgery (figure 2).

However, after approximately 5 years, there was a rapid increase in reoperation rates for patients aged 18-64 years receiving $\mathrm{BV}$, such that by the 10 -year mark, they had a threefold greater rate of reoperation than patients receiving MV (12\% vs 4\%). Among older patients, the rate of reoperation was consistently low. These findings were similar for both sexes (online supplemental figure 2).

\section{Incident cardiovascular event rates}

Rates of incident cardiovascular events (hospital admission or death) were low across age groups and valve types (table 2). In the first 5 years of follow-up, across all ages, there were significant differences favoring BV for AMI, stroke and hemorrhage: (IRR: $0.77,95 \%$ CI 0.60 to 0.98 ); (IRR: $0.75,95 \%$ CI 0.63 to 0.89 ); (IRR: $0.66,95 \%$ CI 0.54 to 0.82 ), respectively. Age-stratified analyses show that patients aged 18-64 years implanted with BV had lower rates of stroke (IRR: $0.40,95 \%$ CI 0.27 to 0.60 ) and hemorrhage (IRR: $0.36,95 \% \mathrm{CI} 0.26$ to 0.50 ) compared with those implanted with MV. Among older patients, those implanted with BV had lower rates of AMI and hemorrhage: (IRR: $0.71,95 \%$ CI 0.53 to 0.96 ) and (IRR: $0.77,95 \%$ CI 0.62 to 0.95 ), respectively.

After 6-10 years of follow-up, rates of AMI among patients aged 18-64 years were lower in those implanted with BV compared with MV (IRR: $0.49,95 \%$ CI 0.26 to $0.94)$. There were no other significant differences in incident cardiovascular events among older patients.

\section{Cardiovascular and all-cause mortality rates}

In the first 5 years of follow-up, rates of cardiovascular and all-cause mortality were lower in patients implanted with BV compared with MV, in the overall cohort (IRR: 0.90, 95\% CI 0.82 to 0.98 and IRR: $0.90,95 \%$ CI 0.84 to 0.97 , respectively) and 65 years and over (IRR: $0.80,95 \%$ CI 0.69 to 0.92 and IRR: $0.85,95 \%$ CI 0.74 to 0.97 ). The agestratified findings for younger patients were not statistically significant.

Between 6-10 years of follow-up, rates of cardiovascular and all-cause mortality across all ages and in patients aged 18-64 years did not differ significantly according to valve type. However, patients aged 65 years and over and implanted with BV had significantly lower rates of both all-cause and cardiovascular mortality (IRR: 0.69, $95 \%$ CI 0.59 to 0.81 and IRR: $0.85,95 \%$ CI 0.75 to 0.95 , respectively). The cumulative incidence curves for cardiovascular mortality were similar for both valve types for younger patients until approximately 6years follow-up, where we saw a higher rate among patients implanted with BV (figure 3). Between 6-10 years of follow-up among older patients, those implanted with MV had slightly higher rates. Kaplan-Meier survival curves for all-cause mortality showed higher rates among young patients with BV and very similar rates for older patients (figure 4). Mortality findings were similar by sex (online supplemental figure 3 and online supplemental figure 4). The top causes of cardiovascular mortality are presented in online supplemental figure 5 and online supplemental figure 6 and crude incident event rates are reported in online supplemental table 4 .

\section{Sensitivity analysis}

Mortality rates within 30 days of the index AVR procedure did not differ significantly between patients implanted with $\mathrm{BV}$ and $\mathrm{MV}$, overall (3.5\% vs 2.9\%), for patients aged $18-64$ years $(2.1 \%$ vs $1.7 \%$, respectively) or for older patients 


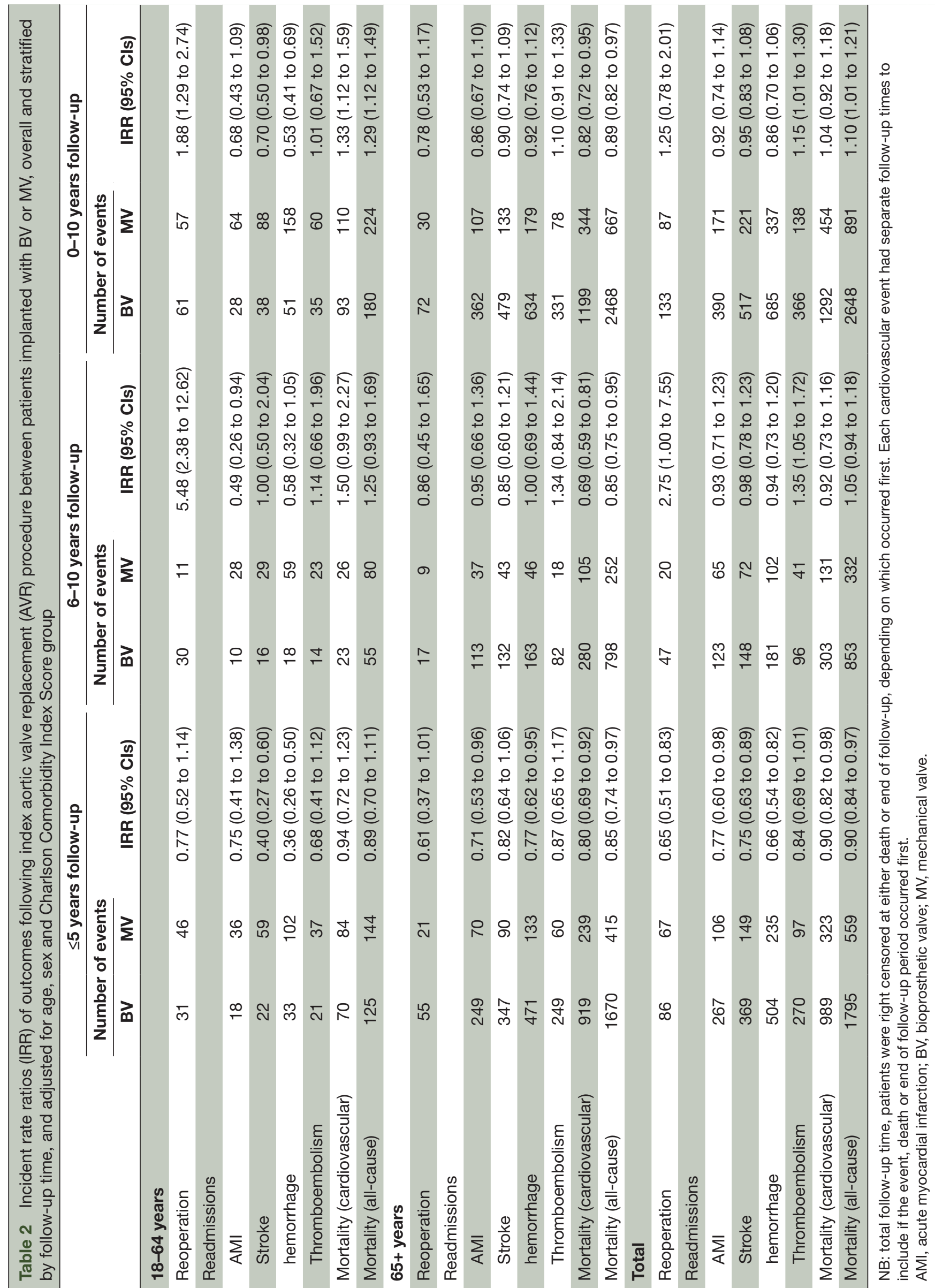




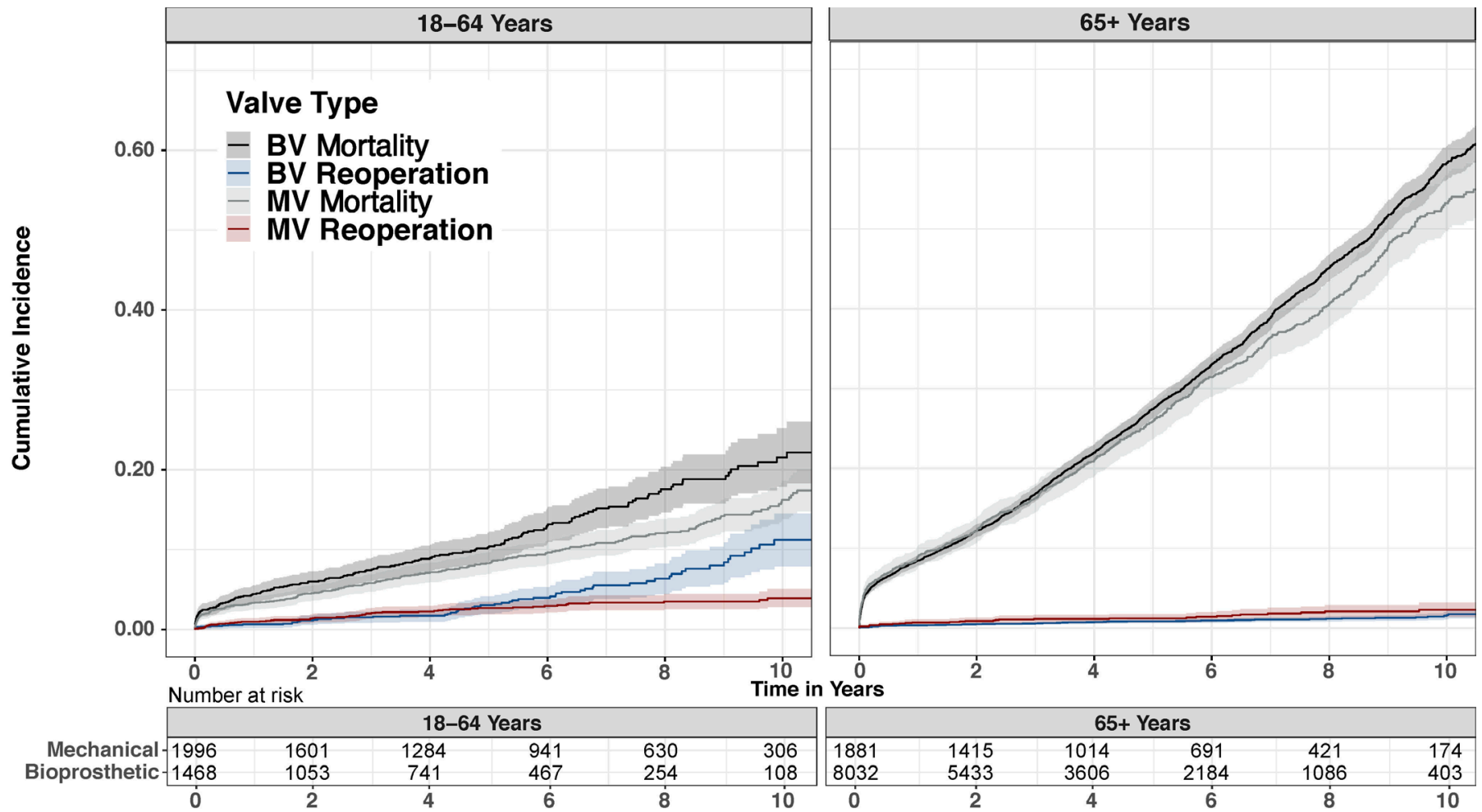

Figure 2 Cumulative incidence curves for reoperation following index aortic valve replacement (AVR) procedure, by valve type and age group. BV, bioprosthetic valve; MV, mechanical valve.

(3.8\% vs $4.2 \%$, respectively). After excluding patients who died within 30 days of their index procedure $(n=9167$ for BV and $\mathrm{n}=3764$ for MV), IRRs for cardiovascular mortality remained similar to the main analysis (online supplemental table 5). We did not observe any notable differences in the results for reoperation and other cardiovascular events between the main and sensitivity analyses. Crude incident event rates are reported in online supplemental table 6.

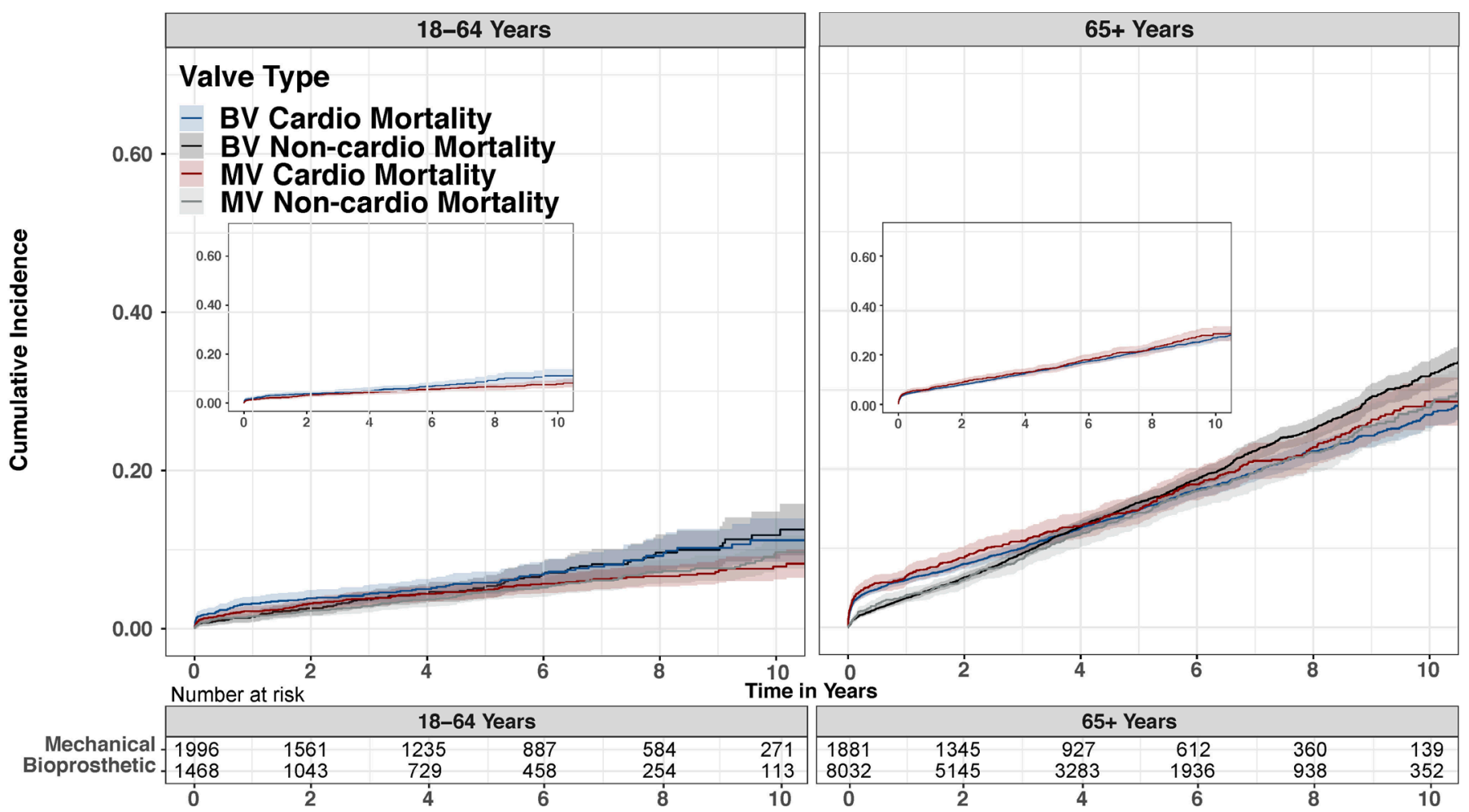

Figure 3 Cumulative incidence curves for cardiovascular mortality following index aortic valve replacement (AVR) procedure, by valve type and age group (inset represents cardiovascular mortality only by valve type). 


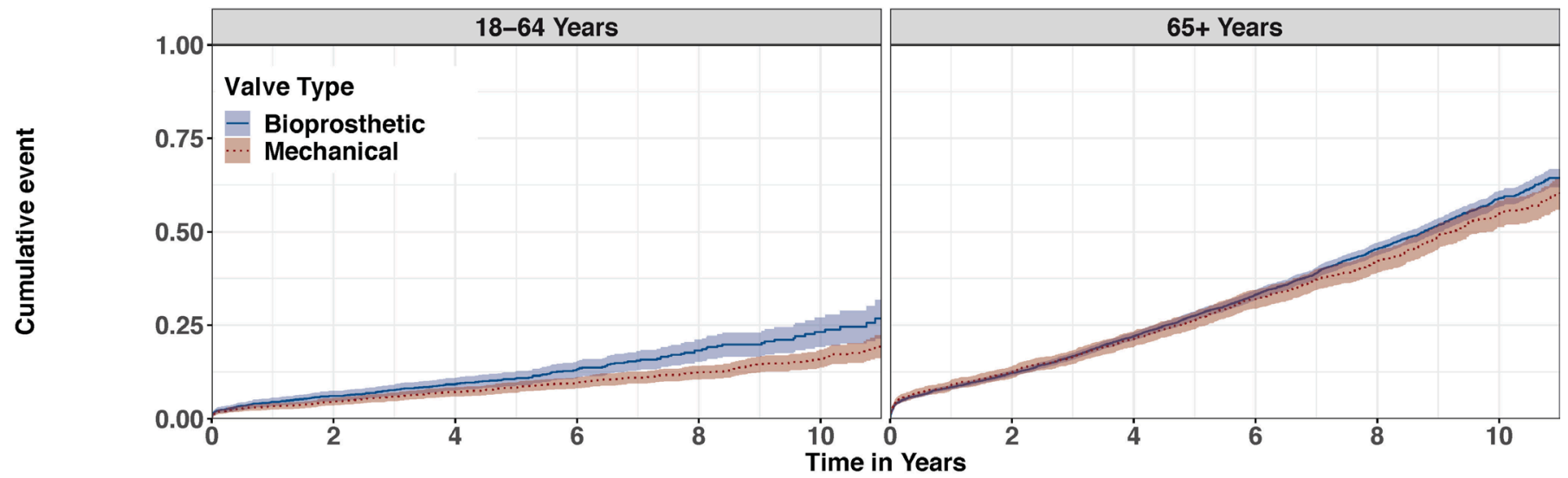

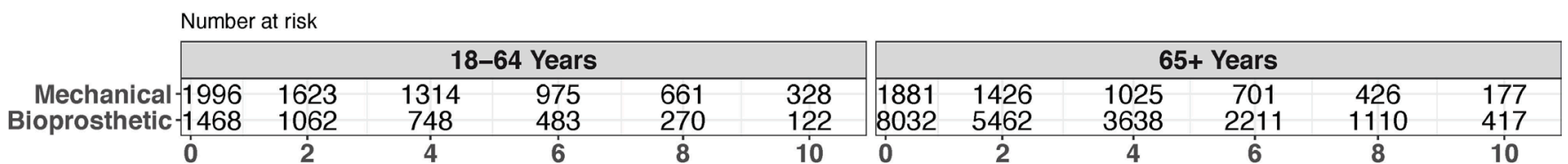

Figure 4 Time to all-cause mortality following index aortic valve replacement (AVR) procedure, by valve type and age group. $\mathrm{BV}$, bioprosthetic valve; MV, mechanical valve.

\section{DISCUSSION}

In this whole-of-population observational cohort study, we showed that increasing rates of surgical AVR are driven predominantly by large increases in BV implants in older patients and marginal increases in younger patients. Importantly, we found that the outcomes of AVR according to valve type vary markedly with patient age. Among patients aged 18-64 years, those implanted with BV rather than MV had a lower risk of stroke and hemorrhage in the first 5 years, and a lower risk of AMI and dramatically increased risk of reoperation after 5 years. Older patients implanted with BV had lower risk of AMI and hemorrhage in the first 5 years, and a significantly lower risk of cardiovascular and all-cause mortality both up to and after 5 years.

Our reoperation rates are consistent with recent systematic reviews. ${ }^{625}$ The Veterans Affairs RCT comparing longterm survival and valve-related complications by valve type $^{10}$ reported that 15 -year reoperation was significantly higher for patients receiving BV. More recent trials have reported similar results for 20 -year ${ }^{47}$ and 17 -year reoperations. ${ }^{24}$ This highlights the concern around using $\mathrm{BV}$ in younger patients, given the increasing risk of morbidity and mortality with each subsequent AVR procedure. ${ }^{7}$ However, our findings suggest that the gains of valve durability with MV may be achieved at the cost of increased incidence of hemorrhage and stroke in the first 5 years postprocedure.

We found that patients aged 18-64 years implanted with BV had significantly higher cardiovascular and all-cause mortality for $0-10$ years of follow-up. This was consistent with a recent systematic review of studies in patients aged $50-70$ years. ${ }^{26}$ A previous $\mathrm{RCT}^{24}$ also reported significantly higher all-cause mortality associated with use of $\mathrm{BV}$ in patients aged $45-54$ years, but not in patients aged 55-64 years. The higher mortality rate in younger patients implanted with $\mathrm{BV}$ in our study may be linked to valve selection being based on the perceived likelihood of survival, with newer guidelines recommending use of BV for frail patients. Patients in our study 18-64 years of age who received BV rather than MV had a slightly higher number of comorbidities, but were less likely to have a concomitant CABG procedure. It is possible the higher mortality rate observed in patients implanted with $\mathrm{BV}$ may be explained by greater clinical complexity. However, our sensitivity analysis excluding patients who died within 30 days of the procedure-presumably those with highest baseline risk of mortalityalso confirmed a higher rate of mortality for younger patients implanted with BV. While we did not observe a significant difference in mortality for patients aged 18-64 years within follow-up time $(0-5$ years, or $6-10$ years $)$, the significant effect over $0-10$ years of follow-up period is likely due to increased statistical power.

Among older patients, we found that use of BV rather than MV was associated with a significantly lower rate of cardiovascular and all-cause mortality. As patients implanted with BV had a lower number of Charlson comorbidities, this mortality difference may also reflect differences in patient clinical complexity, as well as the associated risk of anticoagulants. Some of the differences may also be due to postoperative mortality following reoperation. The existing evidence regarding mortality by valve type for older patients-who make up the vast majority of patients in most previous studiesis inconsistent. The Veterans Affairs Trial, ${ }^{10}$ in which $47.2 \%$ of patients were aged over 60 years, reported better overall survival for patients receiving MV. In another $\mathrm{RCT}^{23}$ among middle-aged to older patients 
(aged 55-70 years), the two valve groups had similar survival rates. Observational studies using propensity score matching methods have variously found that overall survival is better for patients receiving MV or that there is no difference in mortality between valve types, ${ }^{22}{ }^{48-50}$ which was also the conclusion of a systematic review. ${ }^{25}$ The inconsistencies in findings may reflect variation in age inclusion criteria and patient selection between studies.

Our findings on hemorrhage are also consistent with previous studies $^{10111923274751-56}$ and guidelines on the expected risk of placing patients receiving MV on anticoagulation therapy. ${ }^{4}$ Hemorrhage is considered the main driver of mortality, suggesting the risk of reoperation is favored when compared with the known risk of anticoagulant use. ${ }^{25}$ However, our results for younger patients do not support this, although patients aged 18-64 years implanted with MV had a higher incidence of hemorrhage.

Uniquely, we observed a higher incidence of AMI among younger patients receiving MV only after 5 years of follow-up. This effect remained significant in our sensitivity analysis excluding patients who died within 30 days. The median follow-up time to AMI was 3.4 years (IQR 1.4-5.4), and we hypothesize that as a result of increased use of BV in more recent years, younger patients implanted with $\mathrm{BV}$ in our cohort had a shorter median follow-up time (4.1 years, IQR 1.7-7.0) than those implanted with MV (5.9 years, IQR 2.9-9.0), and so BV patients had less follow-up time in which to experience AMI. Conversely, among older BV patients, we observed a lower risk of AMI within the first 5 years of follow-up.

\section{LIMITATIONS}

The linked administrative health data used in this study are valuable for investigating outcomes following surgery because they provide full population coverage. However, they include only limited information on patient risk factors and clinical complexity, limiting our ability to explore how patient selection, as well as valve choice, influenced the observed differences in outcomes between patients who received $\mathrm{BV}$ and MV. A further limitation of the use of administrative data was that it was not possible to know whether the identified index procedure was in fact the first AVR surgery for each patient. Given the average interval between AVR procedures ranges from 5 years to 10 years, it was not feasible to use a 'wash-out' period to exclude patients who may have had an AVR procedure prior to the study period. We attempted to mitigate this limitation by using the ACHI reoperation for cardiac procedures code (38640-00) to identify and exclude reoperations. Further, because we used hospital data for one Australian state only, out-of-state hospitalizations, reoperations or death may have been missed.

\section{CONCLUSIONS}

Our study provides real-world evidence to examine the impact of AVR valves on patient reoperation, cardiovascular events and mortality. It adds to the consensus that use of BV in younger patients increases risk of reoperation, while MV presents risks associated with use of anticoagulation therapy. Our findings urge caution and indicate that choice of valve implant in patients requires thorough evaluation of patient factors influencing both short-term outcomes and the longer-term risks of reoperation, stroke, hemorrhage and mortality. These results from Australia are important considering widespread worldwide adoption of TAVRs in lower-risk groups, and the lack of information about their outcomes, especially in younger patients. Ongoing studies using real-world data as it accumulates are required to provide this evidence.

Acknowledgements The authors thank the New South Wales Ministry of Health and the New South Wales Register of Births, Deaths and Marriages for allowing access to the data, and the Centre for Health Record Linkage for conducting the probabilistic linkage of records.

Contributors OTS, MOF, S-AP, LJ made substantial contributions to the study concept and design. OTS had full access to the study data. Authors OTS and MOF substantially contributed to the analytical protocol and were responsible for executing the statistical analyses. MOF, LNG, S-AP and LJ made substantial contributions to the interpretation of the data. OTS drafted the manuscript and all authors OTS, MOF, LNG, S-AP and LJ revised it critically for important content. All authors OTS, MOF, LNG, S-AP and LJ have approved the final version of the manuscript.

Funding Data were provided by the Indigenous Health Outcomes Patient Evaluation (IHOPE) Study, supported by a National Health and Medical Research Council Project Grant (no: 573113). OTS is supported by an UNSW Scientia PhD scholarship. MOF is supported by an NHMRC Early Career Research Fellowship (no: 1139133).

Competing interests None declared.

Patient consent for publication Not required.

Ethics approval The NSW Population and Health Services Research Ethics Committee (2009/03/141) and the NSW Aboriginal Health and Medical Research Council Ethics Committee (Ref no. 684/09).

Provenance and peer review Not commissioned; externally peer reviewed.

Data availability statement No data are available. The data sets used in this article are available from the Ministry of Health and the Register of Births, Deaths and Marriages, New South Wales (NSW), Australia. The NSW Centre for Health Record Linkage linked the data sets for this study. These data are available to researchers on request and subject to approval from the relevant data custodians and ethics committees, as outlined on the NSW Centre for Health Record Linkage website (http://www.cherel.org.au/).

Open access This is an open access article distributed in accordance with the Creative Commons Attribution Non Commercial (CC BY-NC 4.0) license, which permits others to distribute, remix, adapt, build upon this work non-commercially, and license their derivative works on different terms, provided the original work is properly cited, appropriate credit is given, any changes made indicated, and the use is non-commercial. See: http://creativecommons.org/licenses/by-nc/4.0/.

\section{ORCID iDs}

Oluwadamisola Temilade Sotade http://orcid.org/0000-0003-2291-1078

Michael Falster http://orcid.org/0000-0001-6444-7272

Sallie-Anne Pearson http://orcid.org/0000-0001-7137-6855

Louisa R Jorm http://orcid.org/0000-0003-0390-661X

\section{REFERENCES}

1 Carabello BA, Paulus WJ. Aortic stenosis. Lancet 2009;373:956-66. 
2 lung B, Baron G, Butchart EG, et al. A prospective survey of patients with valvular heart disease in Europe: the Euro heart survey on valvular heart disease. Eur Heart J 2003;24:1231-43.

3 De Sciscio P, Brubert J, De Sciscio M, et al. Quantifying the shift toward transcatheter aortic valve replacement in low-risk patients: a meta-analysis. Circ Cardiovasc Qual Outcomes 2017;10:e003287.

4 Baumgartner H, Falk V, Bax JJ, et al. 2017 ESC/EACTS guidelines for the management of valvular heart disease. Eur Heart $J$ 2017;38:2739-91.

5 Nishimura RA, Otto CM, Bonow RO, et al. AHA / ACC Guideline 2014 AHA / ACC Guideline for the Management of Patients With Valvular Heart Disease : Executive Summary A Report of the American College of Cardiology / American Heart Association Task Force on Practice Guidelines 2014

6 Head SJ, Çelik M, Kappetein AP. Mechanical versus bioprosthetic aortic valve replacement. Eur Heart J 2017;38:2183-91.

7 Nishimura RA, Otto CM, Bonow RO, et al. 2017 AHA/ACC Focused Update of the 2014 AHA/ACC Guideline for the Management of Patients With Valvular Heart Disease: A Report of the American College of Cardiology/American Heart Association Task Force on Clinical Practice Guidelines. J Am Coll Cardiol 2017;70:252-89.

8 Niclauss L, von Segesser LK, Ferrari E. Aortic biological valve prosthesis in patients younger than 65 years of age: transition to a flexible age limit? Interact Cardiovasc Thorac Surg 2013;16:501-7.

9 BR O, CB A, Kanu C, et al. ACC/AHA 2006 guidelines for the management of patients with valvular heart disease. Circulation 2006;114:e84-231.

10 Hammermeister K, Sethi GK, Henderson WG, et al. Outcomes 15 years after valve replacement with a mechanical versus a bioprosthetic valve: final report of the Veterans Affairs randomized trial. J Am Coll Cardiol 2000;36:1152-8.

11 Khan SS, Trento A, DeRobertis M, et al. Twenty-Year comparison of tissue and mechanical valve replacement. J Thorac Cardiovasc Surg 2001;122:257-69.

12 Mohr FW. Decade in review--valvular disease: Current perspectives on treatment of valvular heart disease. Nat Rev Cardiol 2014;11:637.

13 Sedrakyan A, Dhruva SS, Sun T, et al. Trends in use of transcatheter aortic valve replacement by age. JAMA 2018;320:598-600.

14 Isaacs AJ, Shuhaiber J, Salemi A, et al. National trends in utilization and in-hospital outcomes of mechanical versus bioprosthetic aortic valve replacements. J Thorac Cardiovasc Surg 2015;149:1262-9.

15 Sedrakyan A, Dhruva SS, Shuhaiber J. Transcatheter aortic valve replacement in younger individuals. JAMA Intern Med 2017;177:159-60.

16 Dunning J, Gao H, Chambers J, et al. Aortic valve surgery: marked increases in volume and significant decreases in mechanical valve use--an analysis of 41,227 patients over 5 years from the Society for Cardiothoracic Surgery in Great Britain and Ireland National database. J Thorac Cardiovasc Surg 2011;142:776-82.

17 Lee R, Li S, Rankin JS, et al. Fifteen-Year Outcome Trends for Valve Surgery in North America. Ann Thorac Surg 2011;91:677-84.

18 Si S, Hillis GS, Sanfilippo FM, et al. Surgical aortic valve replacement in Australia, 2002-2015: temporal changes in clinical practice, patient profiles and outcomes. ANZ J Surg 2019;0.

19 Peterseim DS, Cen YY, Cheruvu S, et al. Long-Term outcome after biologic versus mechanical aortic valve replacement in 841 patients. J Thorac Cardiovasc Surg 1999;117:890-7 https://doi.org/

20 Brown ML, Schaff H V, Lahr BD, et al. Aortic valve replacement in patients aged 50 to 70 years: Improved outcome with mechanical versus biologic prostheses. J Thorac Cardiovasc Surg 2008;135:87884.

21 Glaser N, Jackson V, Holzmann MJ, et al. Aortic valve replacement with mechanical vs. biological prostheses in patients aged 50-69 years. Eur Heart J 2016;37:2658-67.

22 Chiang YP, Chikwe J, Moskowitz AJ, et al. Survival and longterm outcomes following bioprosthetic vs mechanical aortic valve replacement in patients aged 50 to 69 years. JAMA 2014;312:1323-9.

23 Stassano P, Di Tommaso L, Monaco M, et al. Aortic valve replacement: a prospective randomized evaluation of mechanical versus biological valves in patients ages 55 to 70 years. J Am Coll Cardiol 2009;54:1862 LP-8.

24 Goldstone AB, Chiu P, Baiocchi M, et al. Mechanical or biologic prostheses for aortic-valve and mitral-valve replacement. $N$ Engl J Med 2017;377:1847-57

25 Zhao DF, Seco M, Wu JJ, et al. Mechanical versus bioprosthetic aortic valve replacement in middle-aged adults: a systematic review and meta-analysis. Ann Thorac Surg 2016;102:315-27.

26 Diaz R, Hernandez-Vaquero D, Alvarez-Cabo R, et al. Long-Term outcomes of mechanical versus biological aortic valve prosthesis: systematic review and meta-analysis. J Thorac Cardiovasc Surg 2019:158:706-14.

27 Head SJ, Çelik M, Kappetein AP. Mechanical versus bioprosthetic aortic valve replacement. Eur Heart J 2017;38:2183-91.

28 lung B, Vahanian A. Epidemiology of valvular heart disease in the adult. Nat Rev Cardiol 2011;8:162-72.

29 De Sciscio P, Brubert J, De Sciscio M. Aortic stenosis in Australia: disease prevalence and patient eligibility for aortic valve replacement. Heart, Lung and Circulation 2015;24:S409.

30 Mylotte D, Osnabrugge RLJ, Windecker S, et al. Transcatheter aortic valve replacement in Europe: adoption trends and factors influencing device utilization. J Am Coll Cardiol 2013;62:210-9.

31 Australian Institute of Health and Welfare. Australia's health 2018. Australia's health series no. 16. AUS 221. Canberra, 2018.

32 National Centre for Classification in Health (Australia). The International statistical classification of diseases and related health problems, 10th revision, Australian modification (ICD-10-AM): Australian classification of health interventions (ACHI. National Centre for Classification in Health, 2006.

33 Centre for Health Record Linkage. How record linkage works. Sydney, Australia, 2011. Available: http://www.cherel.org.au/howrecord-linkage-works [Accessed 7 Jul 2019].

34 Centre for Health Record Linkage. Quality assurance, 2012. Available: https://www.cherel.org.au/quality-assurance [Accessed 8 May 2020].

35 Sundararajan V, Henderson T, Perry C, et al. New ICD-10 version of the Charlson comorbidity index predicted in-hospital mortality. J Clin Epidemiol 2004;57:1288-94.

36 Australian Bureau of Statistics. 2039.0 - Information Paper: An Introduction to Socio-Economic Indexes for Areas (SEIFA), 2006. Canberra, 2008.

37 Australian Institute of Health and Welfare. Regional and remote health: a guide to remoteness classifications. Canberra, 2004

38 Russell EA, Reid CM, Walsh WF, et al. Outcome following valve surgery in Australia: development of an enhanced database module. BMC Health Serv Res 2017;17:1-5.

39 Guimarães PO, Krishnamoorthy A, Kaltenbach LA, et al. Accuracy of Medical Claims for Identifying Cardiovascular and Bleeding Events After Myocardial Infarction : A Secondary Analysis of the TRANSLATE-ACS Study. JAMA Cardiol 2017;2:750-7.

40 Öhman L, Johansson $\mathrm{M}$, Jansson $\mathrm{J}-\mathrm{H}$, et al. Positive predictive value and misclassification of diagnosis of pulmonary embolism and deep vein thrombosis in Swedish patient registries. Clin Epidemiol 2018;10:1215-21.

41 Lawrence $\mathrm{K}$, Joos $\mathrm{C}$, Jones $\mathrm{AE}$, et al. Assessing the accuracy of ICD-10 codes for identifying acute thromboembolic events among patients receiving anticoagulation therapy. J Thromb Thrombolysis 2019;48:181-6.

42 Akins CW, Miller DC, Turina MI, et al. Guidelines for reporting mortality and morbidity after cardiac valve interventions. $J$ Thorac Cardiovasc Surg 2008;135:732-8

43 Ye S. Cardiac Events. In: Gellman MD, Turner JR, eds. Encyclopedia of behavioral medicine. New York, NY: Springer New York, 2013: 331-2.

44 Vahanian A, Baumgartner H, Bax J, et al. Guidelines on the management of valvular heart disease: the task force on the management of valvular heart disease of the European Society of cardiology. Eur Heart J 2007;28:230-68.

45 Australian Bureau of Statistics. 3101.0 - Australian Demographic Statistics, Dec 2018. 'Table 51. Estimated Resident Population By Single Year Of Age, New South Wales', time series spreadsheet. Canberra: 2019, 2018. Available: https://www.abs.gov.au/ AUSSTATS/abs@.nsf/DetailsPage/3101.0Dec

46 Australian Bureau of Statistics. Standard population for use in AgeStandardisation table. Canberra, 2013. Available: https://www.abs. gov.au/AUSSTATS/abs@.nsf/DetailsPage/3101.0Dec

47 Oxenham $\mathrm{H}$, Bloomfield $\mathrm{P}$, Wheatley DJ, et al. Twenty year comparison of a Bjork-Shiley mechanical heart valve with porcine bioprostheses. Heart 2003;89:715-21.

48 Alex S, Hiebert B, Arora R, et al. Survival and long-term outcomes of aortic valve replacement in patients aged 55 to 65 years. Thorac Cardiovasc Surg 2018;66:313-21.

49 Chikwe J, Chiang YP, Egorova NN, et al. Survival and outcomes following bioprosthetic vs mechanical mitral valve replacement in patients aged 50 to 69 YearsBioprosthetic vs mechanical mitral valve outcomes among older PatientsBioprosthetic vs mechanical mitral valve outcomes among older patient. JAMA 2015;313:1435-42.

50 McClure RS, McGurk S, Cevasco M, et al. Late outcomes comparison of nonelderly patients with stented bioprosthetic and mechanical valves in the aortic position: a propensity-matched analysis. J Thorac Cardiovasc Surg 2014;148:1931-9. 
51 van Geldorp MWA, Eric Jamieson WR, Kappetein AP, et al. Patient outcome after aortic valve replacement with a mechanical or biological prosthesis: weighing lifetime anticoagulant-related event risk against reoperation risk. J Thorac Cardiovasc Surg 2009;137:881-6.

52 Carapetis JR, Powers JR, Currie BJ, et al. Outcomes of cardiac valve replacement for rheumatic heart disease in Aboriginal Australians. The Asia Pacific Heart Journal 1999;8:138-47.

53 Holper K, Wottke M, Lewe T, et al. Bioprosthetic and mechanical valves in the elderly: benefits and risks. Ann Thorac Surg 1995;60:S443-6.
54 Mykén PS, Caidahl K, Larsson P, et al. Mechanical versus biological valve prosthesis: a ten-year comparison regarding function and quality of life. Ann Thorac Surg 1995;60:S447-52.

55 Hammermeister KE, Sethi GK, Henderson WG, et al. A comparison of outcomes in men 11 years after heart-valve replacement with a mechanical valve or bioprosthesis. N Engl J Med 1993;328:1289-96.

56 Bloomfield P, Wheatley DJ, Prescott RJ, et al. Twelve-year comparison of a Bjork-Shiley mechanical heart valve with porcine bioprostheses. N Engl J Med 1991;324:573-9. 